\title{
\begin{tabular}{l|l} 
Mibraries & DSpace@MIT
\end{tabular}
}

\author{
MIT Open Access Articles
}

\section{A Comparison of Atmospheric Reanalysis Products for the Arctic Ocean and Implications for Uncertainties in Air-Sea Fluxes}

The MIT Faculty has made this article openly available. Please share how this access benefits you. Your story matters.

Citation: Chaudhuri, Ayan H., Rui M. Ponte, and An T. Nguyen. "A Comparison of Atmospheric Reanalysis Products for the Arctic Ocean and Implications for Uncertainties in Air-Sea Fluxes." J. Climate 27, no. 14 (July 2014): 5411-5421. (C) 2014 American Meteorological Society

As Published: http://dx.doi.org/10.1175/JCLI-D-13-00424.1

Publisher: American Meteorological Society

Persistent URL: http://hdl.handle.net/1721.1/93872

Version: Final published version: final published article, as it appeared in a journal, conference proceedings, or other formally published context

Terms of Use: Article is made available in accordance with the publisher's policy and may be subject to US copyright law. Please refer to the publisher's site for terms of use. 


\title{
A Comparison of Atmospheric Reanalysis Products for the Arctic Ocean and Implications for Uncertainties in Air-Sea Fluxes
}

\author{
Ayan H. Chaudhuri And Rui M. Ponte \\ Atmospheric and Environmental Research, Lexington, Massachusetts \\ AN T. NGUYEN \\ Massachusetts Institute of Technology, Cambridge, Massachusetts
}

(Manuscript received 18 July 2013, in final form 3 March 2014)

\begin{abstract}
The uncertainties related to atmospheric fields in the Arctic Ocean from commonly used and recently available reanalysis products are investigated. Fields from the 1) ECMWF Interim Re-Analysis (ERAInterim), 2) Common Ocean-Ice Reference Experiment version 2 (CORE2), 3) Japanese 25-yr Reanalysis Project (JRA-25), 4) NCEP-NCAR reanalysis, 5) NCEP Climate Forecast System Reanalysis (CFSR), and 6) Modern-Era Retrospective Analysis for Research and Applications (MERRA) are evaluated against satellite-derived and in situ observations for zonal and meridional winds, precipitation, specific humidity, surface air temperature, and downwelling longwave and shortwave radiation fluxes. Comparison to reference observations shows that for variables such as air temperature and humidity, all reanalysis products have similar solutions. However, other variables such as winds, precipitation, and radiation show large spreads. The magnitude of uncertainties in all fields is large when compared to the signal. Biases in Arctic cloud parameterizations and predicted temperature and humidity profiles in reanalyses as discussed in other studies are likely common sources of error that affect surface downwelling radiation, air temperature, humidity, and precipitation.
\end{abstract}

\section{Introduction}

The Arctic is a region of complex interactions between the atmosphere, the ocean, and sea ice. These interactions give rise to a variety of feedbacks that can severely complicate attempts to understand and project climate change (Houghton et al. 2001). In particular, it is widely accepted that changes in the surface albedo associated with melting snow and ice enhance warming but other processes such as changes in cloud cover and atmospheric water vapor content are also likely contributors. Global climate models have, almost without exception, indicated a polar amplification of global warming in greenhouse experiments (e.g., Houghton et al. 1990; Serreze and Francis 2006). Thus the continuous monitoring and understanding of various dynamical

Corresponding author address: Ayan H. Chaudhuri, Atmospheric and Environmental Research, 131 Hartwell Ave., Lexington, MA 02421.

E-mail: achaudhu@aer.com processes and their complex interaction over the Arctic Ocean is extremely desirable.

Studies of the Arctic Ocean state are limited by the paucity of observations in space and time. Ocean general circulation models mitigate these challenges by providing an alternative platform for synthesis of observations and enable hypothesis testing via numerical experiments. For the Arctic Ocean, modeling has become one of the major instruments for understanding past conditions and explaining recently observed changes (Proshutinsky et al. 2005). For these ocean modeling efforts, near-surface atmospheric state variables are needed to infer forcing air-sea fluxes. The commonly available reanalysis products used to force ocean models include the National Centers for Environmental Prediction-National Center for Atmospheric Research (NCEP-NCAR) reanalysis (Kalnay et al. 1996; Kistler et al. 2001), the 40-yr European Centre for MediumRange Weather Forecasts (ECMWF) Re-Analysis (ERA-40) (Uppala et al. 2005), and the Japanese 25-yr Reanalysis Project (JRA-25) (Onogi et al. 2005). A new 
generation of reanalysis products such as the Modern-Era Retrospective Analysis for Research and Applications (MERRA) (Rienecker et al. 2011), the NCEP Climate Forecast System Reanalysis (CFSR) (Saha et al. 2010), and the ECMWF Interim Re-Analysis (ERA-Interim) (Dee et al. 2011) have since been made available for deriving air-sea fluxes for ocean models. Regional reanalysis for the Arctic has also been made recently (Wilson et al. 2012). However, sparse atmospheric data in the Arctic result in biases and uncertainties in all reanalysis products, which in turn lead to errors in the ocean state estimates.

Surface atmospheric fields are also important for driving sea ice models and computing all the air-ice fluxes. In general a sea ice model has several ice categories. For each category air-ice heat and freshwater fluxes are computed as in the case of air-sea fluxes (Large and Yeager 2004). However, ice models differentiate between snow and rain. The snow accumulates on top of the ice, while the rain is passed directly to the ocean below. Turbulent air-ice fluxes are usually computed by bulk formulas (Large and Yeager 2004). Given a shortwave insolation dataset, ice models have to typically split this radiation into four components: visible direct, visible diffuse, near-infrared direct, and nearinfrared diffuse, together with respective albedos, for each ice category. This complicated partitioning is usually avoided by utilizing downwelling longwave radiation. Thus errors in these fluxes and deficiencies in the ocean and ice models project in unpredictable ways onto the ice-ocean fluxes, and hence the ocean model solution.

Several studies show significant biases in arctic wind stress and its divergence (Holloway and Sou, 2002), polar temperatures and precipitation (Drobot et al. 2006), and the sea surface albedo (Zhang et al. 1995). These biases are corrected in several ways. Large and Yeager (2004) created a dataset called the Coordinated Ocean-Ice Reference Experiment (CORE) that applies corrections to original NCEP-NCAR reanalysis fields by adjusting them against a variety of satellite-based and in situ derived radiation, SST, sea ice concentration, and precipitation products. CORE version 2 (CORE2) (Griffies et al. 2012) has improvements in air temperature and continental runoff, and further corrections to errors found in CORE. Similarly, Hunke and Holland (2007) compare three forcing datasets, all variants of NCEP-NCAR forcing, in global ice-ocean simulations and evaluate them for use in Arctic model studies as part of the Arctic Ocean Model Intercomparison Project. They find that while these forcing datasets have many similarities, the resulting simulations present significant differences, most notably in ice thickness and ocean circulation. Their results underscore the sensitivity of Arctic sea ice and ocean conditions to slight changes in environmental forcing parameters. Jakobson et al. (2012) note that observed biases in reanalysis-derived temperature, humidity, and wind speeds are in many cases comparable to or even larger than the climatological trends during the latest decades.

In this study, our goal is to assess as best as possible the uncertainties in atmospheric fields used to force Arctic ocean and sea ice models. A similar study has been conducted by Chaudhuri et al. (2013) for the global ocean but the datasets used did not cover much of the Arctic Ocean. In this study we use Arctic Ocean-specific datasets (section 2) to derive uncertainties for typical atmospheric forcing fields, which include winds, air temperature, specific humidity, precipitation, and downwelling longwave and shortwave radiation fluxes. We compare several reanalysis, satellite-based, and in situ derived products to estimate uncertainties for each of the mentioned forcing fields (section 3). Uncertainty estimates and characteristic signal-to-noise ratios are presented in section 4, followed by a discussion of common sources of these uncertainties for the different atmospheric variables in section 5 and a summary of our results in section 6 .

\section{Data and methods}

Near-surface atmospheric state fields from five reanalysis products (NCEP-NCAR, ERA-Interim, JRA-25, CFSR, and MERRA) and one reanalysis-derived product (CORE2) are considered for evaluation against corresponding in situ and satellite-derived reference fields from the Global Precipitation Climatology Project (GPCP) (Adler et al. 2003; Huffman et al. 2009), the International Arctic Buoy Program/Polar Exchange at the Sea Surface (IABP/POLES) (Rigor et al. 2000), the International Satellite Cloud Climatology Project (ISCCP) and its surface radiation budget (SRB) (Zhang et al. 2004), the French Research Institute for Exploitation of the Sea (IFREMER) air-sea turbulent flux product (Bentamy et al. 2008), and the Television Infrared Observation Satellite (TIROS)-N Operational Vertical Sounder (TOVS) Polar Pathfinder atmospheric winds for the Arctic (Francis et al. 2005). A list of the products, with further details on resolution, available fields, and temporal coverage, is provided in Table 1. Analyses focus on regions poleward of $60^{\circ} \mathrm{N}$, which include Arctic and sub-Arctic basins.

Three of the reanalysis products in Table 1 are the same as in the global study of Chaudhuri et al. (2013); however, CFSR and MERRA fields are also included in this study. Moreover, different data products are used here for their enhanced coverage in the Arctic and subArctic regions. For instance, Chaudhuri et al. (2013) 
TABLE 1. Analysis periods for different atmospheric parameters, namely, air temperature (Tair), specific humidity (Hum), 10-m wind (U10 and V10), downwelling longwave and shortwave radiation (Lwdn and Swdn), and precipitation (Precip), are largely constrained by the availability of satellite-based data. IFREMER air-sea turbulent flux data are used as reference to compare specific humidity fields from reanalysis products. Similarly GPCP and SRB are used as references for precipitation and radiation components. Nearsurface air temperatures for the buoy-based IABP data are used to compare air temperature fields. TOVS-based data are used to compare winds.

\begin{tabular}{|c|c|c|c|}
\hline Name & Product type (resolution) and source & (Near) Surface variables & Analysis period \\
\hline $\begin{array}{l}\text { NCEP-NCAR } \\
\text { Reanalysis } 1 \text { (R1) }\end{array}$ & $\begin{array}{l}\text { Reanalysis }(\sim 200 \mathrm{~km} \text { and 6-hourly) } \\
\text { Computational and Information Systems } \\
\text { Laboratory (CISL) at NCAR }\end{array}$ & $\begin{array}{l}\text { Tair, Hum, U10, V10, Precip, } \\
\text { Lwdn, and Swdn }\end{array}$ & Based on reference \\
\hline ERA-Interim & $\begin{array}{l}\text { Reanalysis ( } \sim 80 \mathrm{~km} \text { and 6-hourly) } \\
\text { CISL at NCAR }\end{array}$ & $\begin{array}{l}\text { Tair, Hum, U10, V10, Precip, } \\
\text { Lwdn, and Swdn }\end{array}$ & Based on reference \\
\hline JRA-25 & $\begin{array}{l}\text { Reanalysis }(\sim 120 \mathrm{~km} / 6 \text {-hourly }) \\
\text { CISL at NCAR }\end{array}$ & $\begin{array}{l}\text { Tair, Hum, U10, V10, Precip, } \\
\text { Lwdn, and Swdn }\end{array}$ & Based on reference \\
\hline CORE2 & $\begin{array}{l}\text { Corrected NCEP-NCAR R1 } \\
(\sim 200 \mathrm{~km} \text { and 6-hourly and daily) } \\
\text { http://data1.gfdl.noaa.gov/ }\end{array}$ & $\begin{array}{l}\text { Tair, Hum, U10, V10, Precip, } \\
\text { Lwdn, and Swdn }\end{array}$ & Based on reference \\
\hline MERRA & $\begin{array}{l}\text { Reanalysis }\left(2 / 3^{\circ} \times 1 / 2^{\circ} \text { and 6-hourly) }\right. \\
\text { Global Modeling and Assimilation Office } \\
\text { (GMAO) and the Goddard } \\
\text { Earth Sciences Data and Informations } \\
\text { Services Center (GES DISC) }\end{array}$ & $\begin{array}{l}\text { Tair, Hum, U10, V10, Precip, } \\
\text { Lwdn, and Swdn }\end{array}$ & Based on reference \\
\hline CFSR & $\begin{array}{l}\text { Reanalysis ( } 38 \mathrm{~km} \text { and 6-hourly) } \\
\text { CISL at NCAR }\end{array}$ & $\begin{array}{l}\text { Tair, Hum, U10, V10, Precip, } \\
\text { Lwdn, and Swdn }\end{array}$ & Based on reference \\
\hline $\begin{array}{l}\text { TOVS Polar Pathfinder } \\
\text { (Path-P) }\end{array}$ & $\begin{array}{l}\text { Satellite-based reference }(\sim 110 \mathrm{~km} \text { and daily }) \\
\text { http://data.eol.ucar.edu/codiac/dss/id }=106.214\end{array}$ & U10 and V10 & 1992-2005 \\
\hline $\begin{array}{l}\text { IFREMER air-sea flux } \\
\text { (reprocessed version 2008) }\end{array}$ & $\begin{array}{l}\text { Satellite-based reference ( } \sim 120 \mathrm{~km} \text { and weekly) } \\
\text { ftp://ftp.ifremer.fr/ }\end{array}$ & Hum & 1992-2007 \\
\hline IABP/POLES version 1.0 & $\begin{array}{l}\text { In situ buoy network ( } \sim 110 \mathrm{~km} \text { and } 12 \text {-hourly }) \\
\text { http://seaice.apl.washington.edu/AirT/ }\end{array}$ & Tair & 1992-2004 \\
\hline SRB release 3.0 & $\begin{array}{l}\text { Satellite-based reference ( } \sim 110 \mathrm{~km} \text { and daily) } \\
\text { http://eosweb.larc.nasa.gov }\end{array}$ & Lwdn and Swdn & $1992-2007$ \\
\hline GPCP version 2.1 & $\begin{array}{l}\text { Satellite-based reference ( } \sim 280 \mathrm{~km} \text { and daily }) \\
\text { http://precip.gsfc.nasa.gov/ }\end{array}$ & Precip & $1997-2005$ \\
\hline
\end{tabular}

used satellite-derived observations of precipitation and humidity from the Hamburg Ocean Atmosphere Parameters and Fluxes from Satellite Data (HOAPS) product, which has no coverage at higher latitudes, particularly in ice-covered regions (Andersson et al. 2010). Similarly, Quick Scatterometer (QuikSCAT) wind data used by Chaudhuri et al. (2013) only extend to $80^{\circ} \mathrm{N}$. In contrast, the GPCP dataset has spatial coverage for most of the Arctic. Although the IFREMER product has no data beyond $80^{\circ} \mathrm{N}$, it has better coverage than HOAPS for the sub-Arctic region between $60^{\circ}$ and $80^{\circ} \mathrm{N}$ and hence is used as a reference for humidity in this study. Our focus on the Arctic also facilitates the use of regional datasets such as IABP/POLES for air temperature and TOVS Polar Pathfinder for atmospheric winds, which were not considered by Chaudhuri et al. (2013) as they did not have global coverage.

Our methodology follows that of Chaudhuri et al. (2013) and is only briefly outlined here; more details are provided in original paper. Since all the products considered are at different spatial and temporal resolutions
(Table 1), all reanalysis and reference products are regridded to the coarsest grid, that of NCEP-NCAR, to minimize interpolation errors and are averaged over 14-day intervals to match the lowest resolution in the satellite-derived references (7-14-day composites). Each variable is standardized to reanalysis reference levels by using the Large and Yeager (2004) bulk formulas. Given that none of the products can be considered as representing "truth," uncertainties are estimated as the largest differences amongst all combinations of satellite-based and reanalysis products. We note that the individual differences between all pairs of products approximately follow a Gaussian distribution. Errors are partitioned into time-mean and time-variable components, which can have quite different magnitudes (Chaudhuri et al. 2013).

To best understand our methodology, one is encouraged to think about each atmospheric field as a 3D variable with the first two dimensions being spatial coordinates and the third dimension being time. Since all the computations occur on the time dimension, we explain the methodology with respect to an individual 
location or grid point, thus reducing our $3 \mathrm{D}$ variable into a one-dimensional (1D) time series variable for better clarity. At each grid point, for a given pair (e.g., MERRA and CFSR) of products with time series $x$ and $y$ respectively, the time-mean error $E_{m}$ is calculated as $|\bar{x}-\bar{y}|$, where the overbar denotes time averaging, and the timevariable error $E_{v}$ is calculated as the standard deviation of $x-y$. These values are calculated for all possible pairs, that is, 21 pairs for 7 products (6 reanalysis and 1 reference) at each grid point. The maximum of the 21 estimated values of $E_{m}$ and $E_{v}$ is taken as the representative $E_{m}$ and $E_{v}$ at the respective grid point or location. In regions of missing data or fields without a "reference" dataset (e.g., air temperature), $E_{m}$ and $E_{v}$ are estimated from differences only within the reanalysis fields (i.e., from 6 products and 15 pairs). This methodology is particularly useful for the data-sparse Arctic. We note that both the models and reference products themselves have implicit errors and $E_{m}$ and $E_{v}$ derived from them should be interpreted as an estimate of the spread in the product solutions. Furthermore, an analysis for all variables (not presented) indicates that the largest differences originate mostly from reanalysis model-model comparisons, which account for $95 \%$ or more of all the values considered for both $E_{m}$ and $E_{v}$.

The root-mean-square signal-to-noise ratios are evaluated by comparing the estimated errors against the respective atmospheric field. There are several methods of estimating signal-to-noise ratios such as estimating ratios of mean and standard deviations (Trenberth et al. 2000), spectral methods (Dell'Aquila et al. 2007), and EOF decomposition methods (Zhu et al. 2012). In our case, the noise $N$ at each grid point is computed by taking the root-sum-square of the time-mean and time-variable errors: $N=\left(E_{m}^{2}+E_{v}^{2}\right)^{1 / 2}$. The signal for an atmospheric field at each grid point is computed by first estimating the temporal average $F_{m}$ and temporal standard deviation $F_{v}$ for each of the seven (or six if there is no reference) individual products for the entire length of their time series. We then take the maximum values of $F_{m}$ and $F_{v}$ among the seven sets at each grid point, and the signal $S$ is estimated by taking their root-sum-square: $S=\left(F_{m}^{2}+F_{v}^{2}\right)^{1 / 2}$. We choose the maximum signal to be consistent with the maximum error estimates described above.

\section{Comparison of reanalysis products}

A comparison of reanalysis solutions against reference data is conducted to better understand their fidelity to these references and among themselves. Note that some of the "reference" datasets (e.g., GPCP) are assimilated into reanalysis models and hence are not true independent references. Furthermore, these datasets have implicit errors of their own and should not be considered as ground truth. For instance, the Arctic-TOVSderived $10-\mathrm{m}$ wind product uses a bulk difference in TOVS-derived potential temperature between the surface and $900 \mathrm{hPa}$, to better estimate the boundary layer stratification. A drag coefficient is then derived based on the stratification to correct the geostrophic wind to $10 \mathrm{~m}$. With a resolution of $100 \mathrm{~km}$ the accuracy of this estimation in regions such as the marginal ice zones is uncertain. Furthermore, details about the accuracy of calibration and related errors are not available and thus the product could contain substantial biases. Similarly, Smith et al. (2011) caution about the IFREMER product, suggesting that information on heat transfer coefficient and drag coefficients used to derive humidity are not provided. Furthermore, scatterometer rain flags were not applied and hence stresses are particularly poor in regions with frequent rain. The IFREMER method also does not account for atmospheric stratification. In spite of these issues, the high-resolution spatial and temporal coverage provided by these satellite-based datasets make them most suitable for comparison. Moreover, in our calculations we use all combinations of reanalysis and reference products, where in most cases the largest differences are from reanalysis-reanalysis differences.

Figure 1 shows a quantitative evaluation of all reanalyses against the respective satellite and observationbased references using Taylor (2001) diagrams. The Taylor diagram (Fig. 1) provides a statistical summary of how well the reanalysis products match the reference patterns in terms of their correlation, root-mean-square difference, and the ratio of their standard deviations. The radial distances from the origin represent the standard deviations, whereas the azimuthal positions show correlation coefficients. Features that match well with the reference in both amplitude and phase appear closest to the reference point in the diagram (e.g., CORE2 shortwave radiation in Fig. 1). Since no restriction is placed on the time or space domain considered, we concatenate the time series at each grid point into a single vector and maintain the same order of concatenation for each dataset. As the units of measurement are different for the different atmospheric variables, their statistics are nondimensionalized by normalizing, for each variable, the RMS difference and the standard deviation by the RMS difference and standard deviation of the corresponding reference variable respectively. This enables us to compare all the fields in one Taylor diagram. We note that the resulting Taylor diagram (Fig. 1) should not be interpreted as an evaluation of the reanalysis products against truth, as the references used here themselves are not free of errors. Rather, the Taylor diagram is used to assess the differences in 

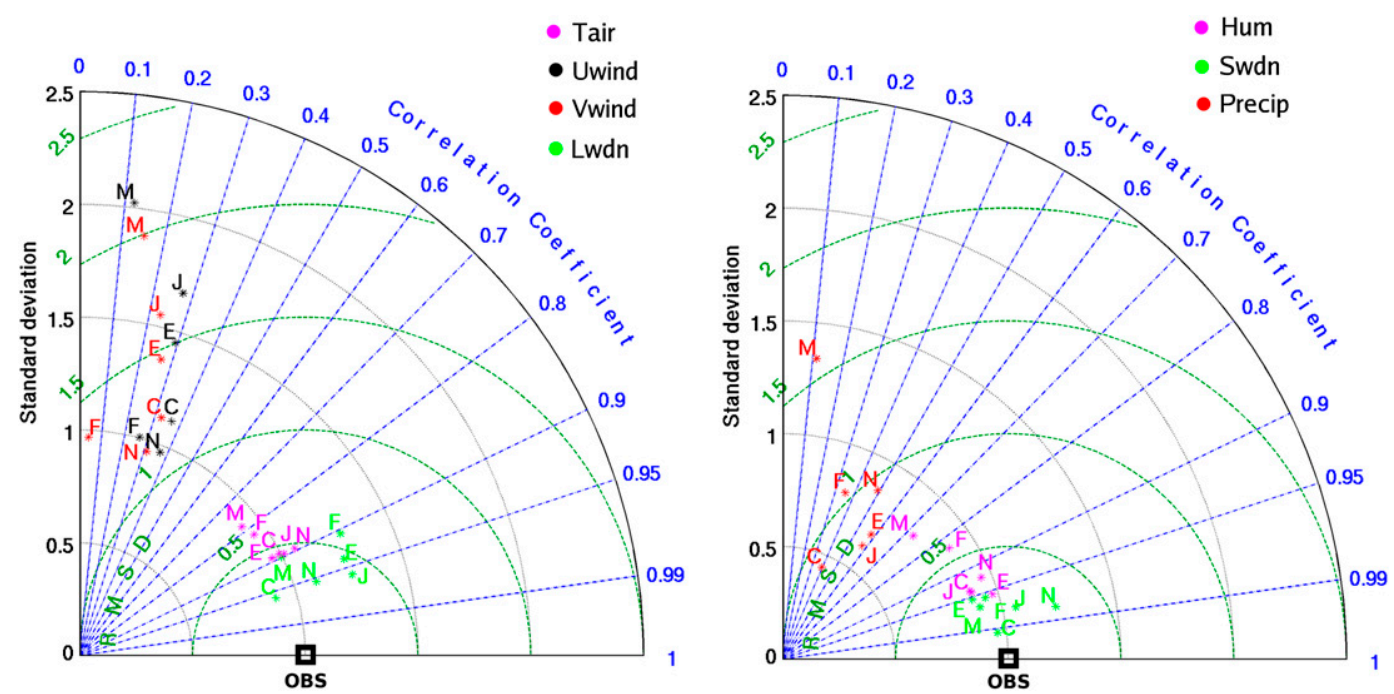

FIG. 1. Taylor diagram representing model performance (Taylor 2001). A polar coordinate system is used, with radius representing the normalized standard deviation, and angle (with respect to horizontal) representing the correlation coefficient, decreasing from 1 to 0 . Green dashed lines show root-mean-square differences. (left) Comparison of satellite-based observations (black dot) against zonal 10-m wind (Uwind), meridional 10-m wind (Vwind), and downwelling longwave radiation (Lwdn) for NCEP-NCAR (N), CORE2 (C), JRA-25 (J), ERA-Interim (E), CFSR (F), and MERRA (M). (right) As in left, but for comparison with precipitation (Precip), humidity (Hum), and downwelling shortwave radiation (Swdn). For time period of analysis refer to Table 1.

reanalysis products when compared against a common reference.

For certain variables such as air temperature, radiation, and humidity, all reanalysis products are clustered around each other (Fig. 1). However, other variables such as $10-\mathrm{m}$ winds and precipitation show large spreads. Furthermore, assessment of individual atmospheric fields suggests that no single product seems to agree better in all fields with reference datasets. Reanalysis products show largest discrepancies in 10-m zonal and meridional winds in comparison to TOVS-derived winds (Fig. 1, left). Note that the TOVS-derived dataset uses NCEP-NCAR 10-m winds as a "first guess" for surface winds, which are then adjusted based on TOVS vertical wind profile data and mass conservation schemes described by Francis et al. (2005). The NCEP-NCAR 10-m winds match well with TOVS data in terms of standard deviations; however, considerable RMS differences $(>1)$ result in weak correlations $(<0.4)$ between the two products. Similarly, CORE2 winds originally derived by adjusting NCEPNCAR wind speeds to QuikSCAT winds also show comparable biases. CFSR $10-\mathrm{m}$ zonal winds show comparable biases to NCEP-NCAR and CORE2 but weaker correlation for meridional 10-m winds. The JRA-25 and ERA-Interim data have comparatively larger biases for 10-m winds in both standard deviation and RMS differences. MERRA 10-m winds show the largest discrepancies with the reference. These biases are in agreement with Francis (2002), who notes that both the NCEP and ECMWF winds are overestimated by as much as $25 \%-$ $65 \%$ when compared to radiosondes that were not assimilated into the reanalysis.

All the reanalysis products seem to display less variability in air temperature [standard deviation $(\mathrm{std})<1$ ] when compared to buoy-based IABP/POLES data, and respective RMS differences are also $>0.5$ (Fig. 1, left). Downwelling longwave (Fig. 1, left) and shortwave radiation (Fig. 1, right) from reanalysis products display differences in variability among themselves but generally correlate well $(>0.9)$ with SRB data. CORE2 fields, which are derived from ISCCP radiation estimates similar to SRB, expectedly demonstrate better agreement than other reanalysis solutions. Precipitation estimates show weak correlation $(<0.6)$ in comparison to the reference and also display large spreads in standard deviations and RMS differences among themselves (Fig. 1, right). MERRA precipitation shows the weakest correspondence to the reference GPCP dataset. The findings related to precipitation here are in contrast to results from Bosilovich et al. (2008), who show better correspondence between GPCP and reanalysis models or regions poleward of $60^{\circ} \mathrm{N}$. However, their analysis is based on annual means or monthly climatologies for January and July, which includes both terrestrial and oceanic regions, whereas this study analyzes only oceanic regions at 14-day averages for the entire period from 1992 to 2005. 

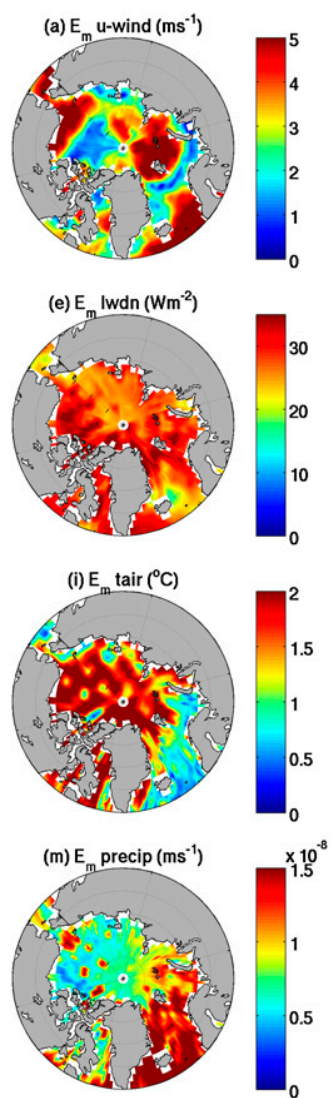
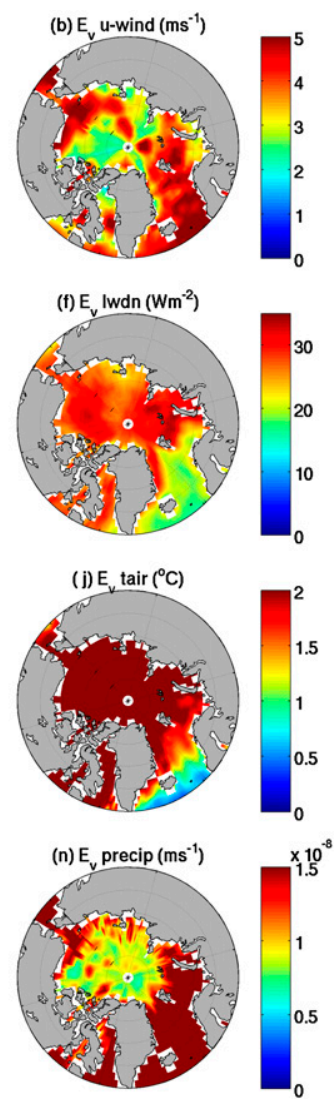
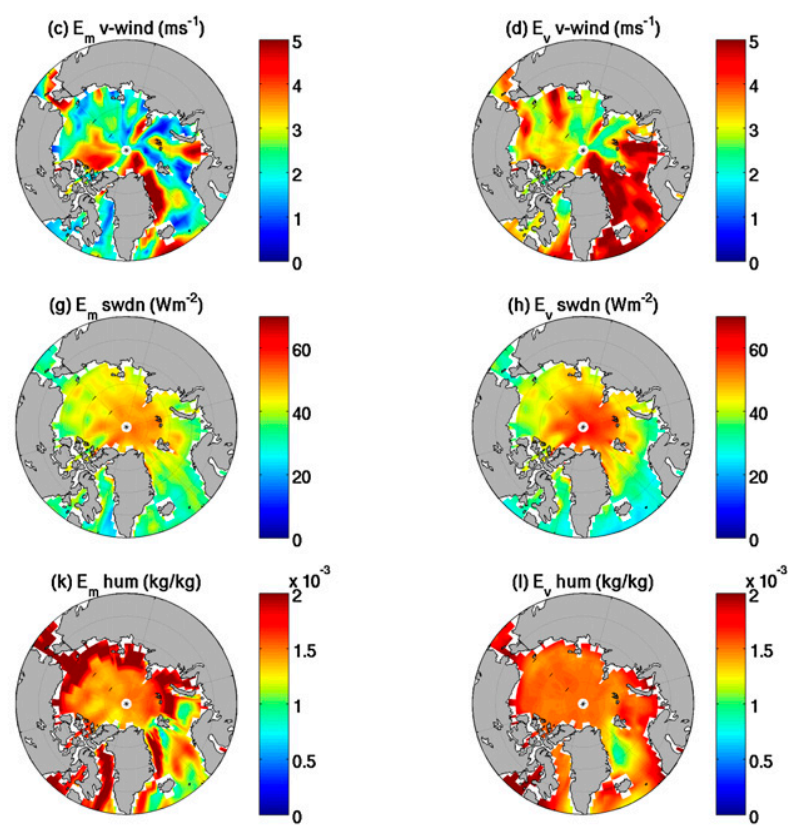

FIG. 2. Estimates of (a) time-mean errors $\left(E_{m}\right)$ and (b) time-variable errors $\left(E_{v}\right)$ in zonal winds, (c) $E_{m}$ and (d) $E_{v}$ in meridional winds, (e) $E_{m}$ and (f) $E_{v}$ in downwelling longwave radiation, (g) $E_{m}$ and (h) $E_{v}$ in downwelling shortwave radiation, (i) $E_{m}$ and (j) $E_{v}$ in air temperature, (k) $E_{m}$ and (l) $E_{v}$ in humidity, and (m) $E_{m}$ and (n) $E_{v}$ in precipitation. For time period of analysis refer to Table 1.

The differences in methodology are likely the main reason for the differences in respective results. Humidity fields display good correspondence with the IFREMER dataset for all the reanalysis products.

\section{Uncertainty estimates}

In this section we present uncertainty estimates of various atmospheric parameters used in forcing ocean general circulation models. The wind errors are computed for the period 1992-2005, which is chosen to coincide with the data available from TOVS. Values of time-mean error $E_{m}$ and time-variable error $E_{v}$ for zonal winds (Figs. 2a,b) tend to be large $\left(>3 \mathrm{~m} \mathrm{~s}^{-1}\right)$ over most of the Arctic except for the Beaufort Sea region. This pattern is coincident with one of two leading $10-\mathrm{m}$ wind modes in the Arctic where southerly and southwesterly wind anomalies originating from the Pacific penetrate the central Arctic and thereafter become northwesterly winds anomalies within the Barents-Kara Seas $(\mathrm{Wu}$ et al. 2012). Meridional 10-m wind is dominated by the other leading mode, that is, the Arctic dipole (Wu et al.
2006), which has a cyclonic pattern in the western Arctic and anticyclonic pattern in the north Greenland and eastern Arctic (Wu et al. 2012). Thus $E_{m}$ and $E_{v}$ in meridional winds (Figs. 2c,d) exhibit large errors $\left(>2 \mathrm{~m} \mathrm{~s}^{-1}\right.$ ) in regions such as the Beaufort Sea along the cyclonic portion of the dipole, and the eastern Greenland coast and northern Kara Sea along the anticyclonic portion.

Values of $E_{m}$ in downwelling longwave radiation (Fig. 2e) are $>25 \mathrm{~W} \mathrm{~m}^{-2}$ in most of the Arctic. Downwelling longwave radiation $E_{v}$ values are $>20 \mathrm{~W} \mathrm{~m}^{-2}$ in the central Arctic and smaller in the marginal and subArctic regions. The central Arctic is dominated by seasonal sea ice extent, which modulates the surface albedo and thus likely affects longwave and shortwave radiation estimates. Furthermore, Tjernström et al. (2008) found a systematic negative bias in downwelling radiation by comparing six regional models from the Arctic Regional Climate Model Intercomparison Project (ARCMIP) against observations from the Surface Heat Budget of the Arctic Ocean (SHEBA) experiment. They conclude that the temporal correlations of some model cloud properties with observations are poor. Most models underestimate 
(a) $\mathrm{S} 2 \mathrm{~N}$ u-wind

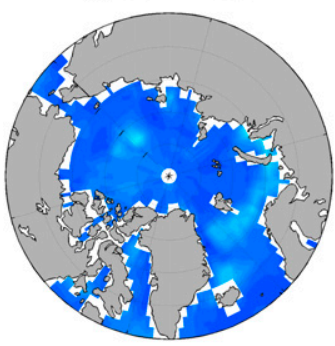

(e) $\mathrm{S} 2 \mathrm{~N}$ air-temp

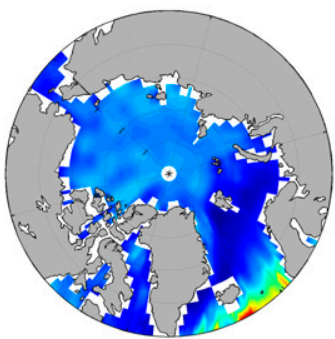

(b) $\mathrm{S} 2 \mathrm{~N}$ v-wind

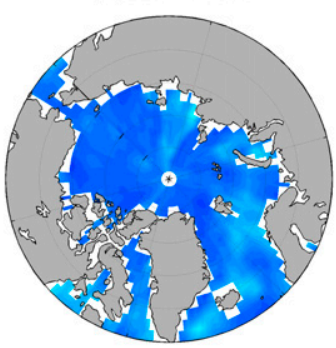

(c) S2N lwdn

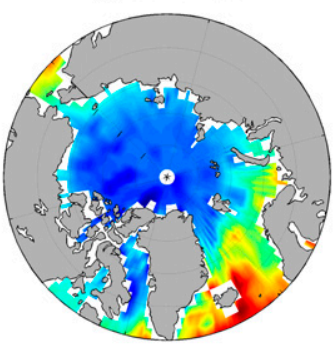

(d) $\mathrm{S} 2 \mathrm{~N}$ swdn

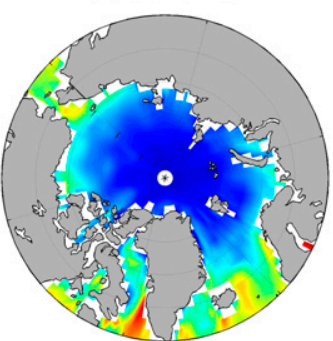

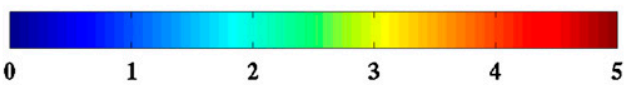

(f) $\mathrm{S} 2 \mathrm{~N}$ hum

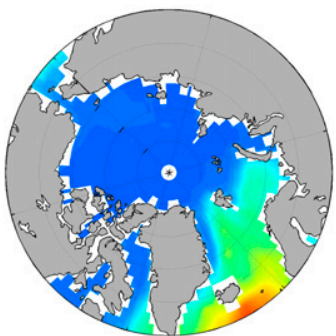

(g) S2N precip

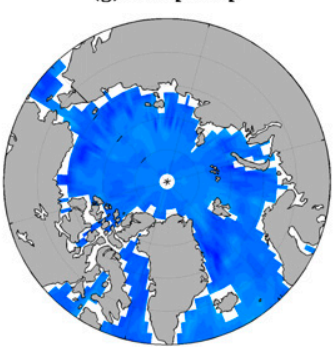

FIG. 3. Signal-to-noise ratios (S2N) of (a) zonal wind, (b) meridional wind, (c) downwelling longwave radiation, (d) downwelling shortwave radiation, (e) air temperature, (f) humidity, and (g) precipitation. The S2N can be converted to percentage of noise by taking the inverse of the plotted values and multiplying by 100 . Thus, regions showing red $(\sim 5)$ can be interpreted as having $20 \%$ noise whereas regions showing blue $(\sim 1)$ can be interpreted as having $100 \%$ or larger noise. For time period of analysis refer to Table 1.

the presence of high clouds, and the modeled low clouds are too thin and displaced downward. Estimates of $E_{m}$ (Fig. $2 \mathrm{~g}$ ) and $E_{v}$ (Fig. $2 \mathrm{~h}$ ) in shortwave radiation show similar spatial patterns with values $>40 \mathrm{~W} \mathrm{~m}^{-2}$ in the central Arctic and smaller values in the sub-Arctic and marginal regions. The shortwave radiation field is also affected by biases in albedo and cloud parameterizations similar to downwelling longwave radiation.

Air temperature uncertainty fields show that $E_{m}$ (Fig. 2i) and $E_{v}$ (Fig. 2j) are both $>2^{\circ} \mathrm{C}$ over most of the Arctic. These uncertainty estimates agree with Rigor et al. (2000), who report uncertainties of nearly $3^{\circ}-5^{\circ} \mathrm{C}$ by comparing data from Arctic buoys against NCEPNCAR and ERA-40 reanalysis values between 1979 and 1997. For humidity, the largest values of $E_{m}(>1.5 \times$ $10^{-3} \mathrm{~kg} \mathrm{~kg}^{-1}$ ) are observed in the coastal regions around the Arctic (Figs. 2k,l); however, a sharp gradient occurs toward the central basin where errors are much smaller. While cold air generally constrains humidity to low values at higher latitudes and hence small humidity errors are expected in the central Arctic, the sharp gradient observed in this study is mainly due to no IFREMER humidity data available in the central Arctic and general agreement among reanalysis fields for the region. The largest values for $E_{v}\left(>1.5 \times 10^{-3} \mathrm{~kg} \mathrm{~kg}^{-1}\right)$ (Fig. 2l) also occur along the coastal regions; however, the gradient between the central Arctic and the coastal regions is not as pronounced as for $E_{m}$ values (Fig. $2 \mathrm{k}$ ). Precipitation $E_{m}$ estimates are $<1 \times 10^{-8} \mathrm{~m} \mathrm{~s}^{-1}$ in the central Arctic with larger values observed in the Greenland-IcelandNorwegian (GIN) Seas (Fig. $2 \mathrm{~m}$ ). Values of $E_{v}$ in precipitation are $>1.5 \times 10^{-8} \mathrm{~m} \mathrm{~s}^{-1}$ at the boundaries of the Arctic Ocean and smaller in the central Arctic (Fig. 2n).

Signal-to-noise ratios (Fig. 3) provide a platform to compare errors in context of the original atmospheric forcing fields and also compare their quality against each other. In general all the fields (Fig. 3) have low signal-tonoise ratios $(<2)$, which is equivalent to noise levels of $>50 \%$ for most of the Arctic Ocean. In particular, the noise in the winds and precipitation fields is high $(>50 \%)$ throughout the Arctic and sub-Arctic regions in comparison to the signal RMS values (Figs. 3a,b,g). Both downwelling longwave (Fig. 3c) and shortwave radiation (Fig. 3d) have noise levels $>50 \%$ in most ice-covered central Arctic regions. The spatial patterns of errors in the radiation fields show distinct signatures between the marginal seas and the central Arctic. In addition to data sparsity issues described earlier, the spatial variability in Fig. 3 is broadly due to the extent of sea ice in the Arctic (Comiso et al. 2008). Differences in sea ice cover and 
simplistic feedback mechanisms in different reanalyses have been noted to affect solutions of downwelling longwave and shortwave radiation (Sorteberg et al. 2007). Thus radiation errors are large over ice-covered regions (Figs. 3c,d). The signal-to-noise ratios for air temperature (Fig. 3e) are low for most of the Arctic regions, but the central Arctic displays lesser noise compared to the subArctic regions. On the contrary, humidity values (Fig. 3f) within the central Arctic have smaller signal-to-noise ratios $(<2)$, whereas the marginal seas show larger signalto- noise ratios $(>2)$. Once again the ice-covered regions have low signal-to-noise ratios for both air temperature and humidity, but in the case of air temperature ice-free regions such as the GIN Seas and the northern Labrador Sea also show small signal-to-noise ratios as opposed to patterns in humidity. The precipitation fields have noise levels $>50 \%$ for both the central Arctic and the subArctic regions (Fig. 3g). Similarly, signal-to-noise ratios in winds do not show any marked differences between central Arctic and marginal seas and appear small for most regions.

In summary, signal-to-noise ratios of near-surface atmospheric variables are small for most of the Arctic. The central Arctic in particular shows high noise levels for all the atmospheric variables. Some fields such as longwave and shortwave as well as humidity show distinct spatial patterns with lower signal-to-noise ratios in ice-covered regions and larger elsewhere. Other fields such as meridional and zonal wind as well as precipitation show low signal-to-noise ratios in most regions.

\section{Discussion}

Atmospheric forcing field uncertainties obtained in this study are large for all fields and show spatial patterns that are broadly segmented into marginal and central Arctic regions. While radiation and air temperature forcing fields show larger errors in the central Arctic and comparatively smaller errors in the marginal and sub-Arctic regions, precipitation and humidity show opposite behavior (Fig. 2). Given these patterns we investigate whether the atmospheric fields have common sources of error. This is done by choosing a commonly studied pair of ERA-Interim and NCEP-NCAR. We take the difference in time series for this pair at each grid point for each forcing variable. For our purposes here, one product is considered the "truth" and the difference between the ERA-Interim and NCEP-NCAR time series (ERA minus NCEP) at each grid point is taken to represent the errors in the respective forcing variable. We thus get one difference time series for each of the seven forcing variables (e.g., $\operatorname{Diff}_{\mathrm{U} 10}=\mathrm{ERA}_{\mathrm{U} 10}-$ $\mathrm{NCEP}_{\mathrm{U} 10}$ and $\left.\operatorname{Diff}_{\mathrm{V} 10}=\mathrm{ERA}_{\mathrm{V} 10}-\mathrm{NCEP}_{\mathrm{V} 10}\right)$. These seven difference time series are then cross correlated with each other-for example, corr( Diff $_{\mathrm{U} 10}$, Diff $\left.\mathrm{V}_{\mathrm{V} 10}\right)$-for all possible combinations at each grid point.

Pairs of fields that yield significant cross correlation at $95 \%$ confidence and show large-scale coherent patterns-mainly in combinations of longwave and shortwave radiation, humidity, air temperature, and precipitation-are shown in Fig. 4. Significant correlation between downwelling shortwave and longwave radiation is largely due to their relationship with clouds, which exert strong control on surface radiation by increasing longwave and reducing shortwave components (Curry et al. 1996) and can thus explain the negative correlation in Fig. 4 (panel denoted by LS). Walsh et al. (2009) compare Arctic radiative fluxes, cloud fraction, and cloud radiative forcing from ERA-40, NCEP-NCAR, and JRA-25 reanalysis fields. They suggest that reanalysis models simulate the radiative fluxes well if and/or when the cloud fraction is simulated correctly. However, the systematic errors of climatological reanalysis cloud fractions are substantial. Cloud fraction and radiation biases show considerable scatter, both in the annual mean and over a seasonal cycle, when compared to observations. Large seasonal cloud fraction biases have significant impacts on the surface energy budget. Persistent lowlevel cloud fraction in summer is particularly difficult for the reanalysis models to capture, creating biases in the shortwave radiation flux that can exceed $160 \mathrm{~W} \mathrm{~m}^{-2}$ (Walsh et al. 2009).

Correlations between actual downwelling longwave radiation and air temperature fields from both NCEPNCAR and ERA-Interim are positive (not shown) for the entire region of study. This physical relation is consistent with the positive cross-correlations in the sub-Arctic regions between longwave radiation and temperature errors (Fig. 4, LT) Relatedly, since warmer air holds more moisture and vice versa, air temperature errors are positively correlated to humidity errors (Fig. 4, QT). As a corollary, downwelling longwave radiation errors are also linked to humidity errors in the sub-Arctic regions (Fig. 4, LQ). Reanalysis-derived downwelling longwave radiation is underestimated in high-latitude cold and dry regions because of biases in the reanalysispredicted thermal and humidity structure in the atmosphere, which enters the radiative transfer calculations (Wild et al. 2001).

Incoming shortwave radiation in the study region is highly seasonal, mostly absent or weak for much of the year, and thus the correlations presented here are largely associated with the short summer season. Under increasing open ocean extent resulting from summer sea ice melting, one expects enhanced shortwave radiation absorption to lead to higher surface air temperature. This 

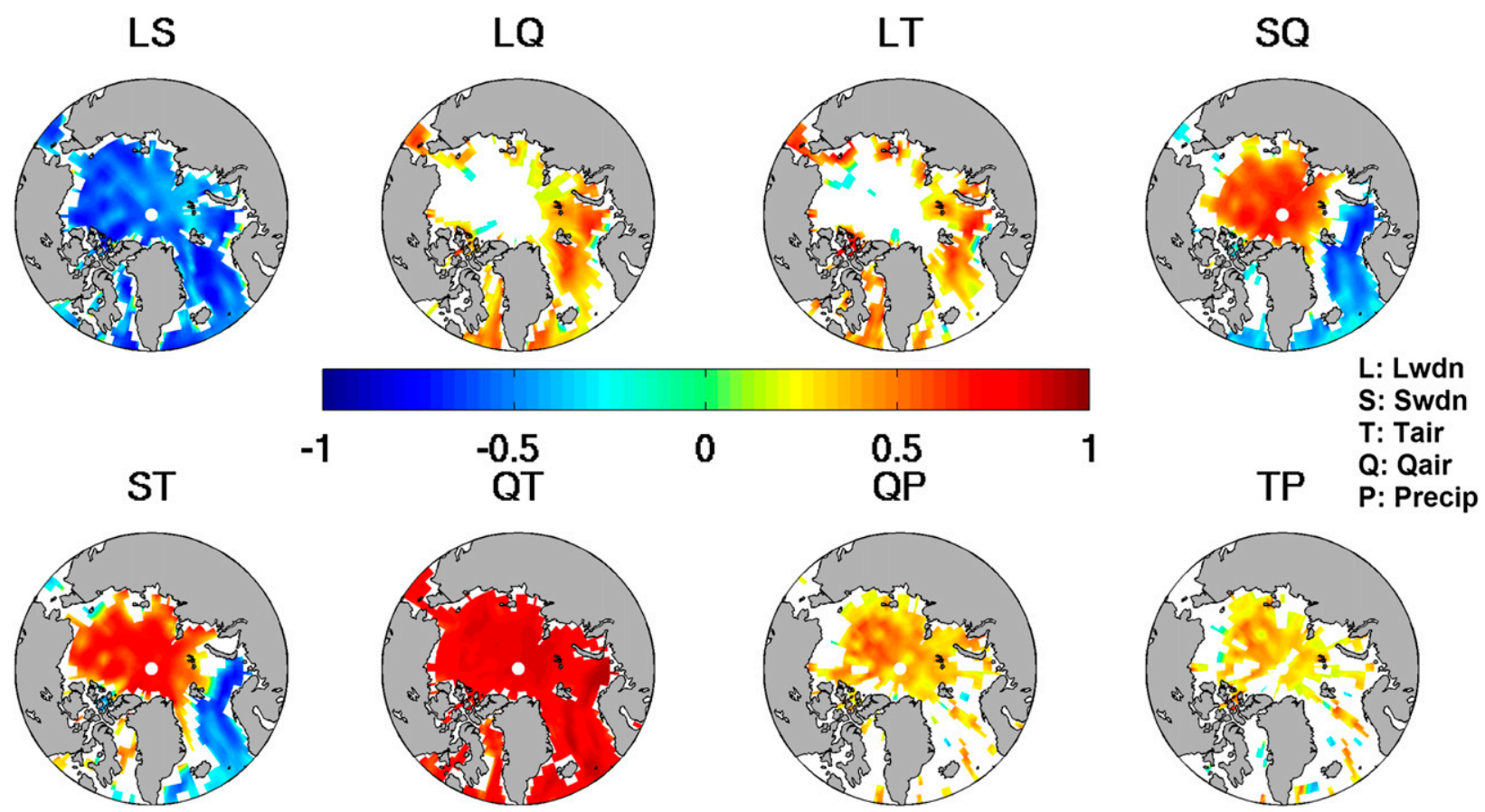

FIG. 4. Significant correlations (95\% confidence) of total errors from differences between ERA-Interim and NCEP-NCAR for various atmospheric fields (e.g., LS means correlation between Lwdn and Swdn; see key at right for other variables, here Qair is humidity). While correlations from all combinations of errors from 7 atmospheric fields were investigated, only fields with significant error correlations are shown. (For clarity of interpretation, positive radiative fluxes represent energy flux into the ocean/ice surface and vice versa.) For time period of analysis and variable definitions refer to Table 1 .

mechanism also applies for perennial open ocean areas (e.g., sub-Arctic regions) and thus errors in shortwave radiation and air temperature are expected to be positively correlated. While this is true for the central Arctic, negative correlations are seen in the GIN and Barents Seas (Fig. 4, ST), where NCEP-NCAR shortwave radiation is consistently larger than in ERA-Interim and summer air temperatures of ERA-Interim are mostly larger than in NCEP-NCAR. The results suggest that the relation between air temperature and shortwave radiation can be complex, involving various physical factors that can lead to both positive and negative correlated errors. The same considerations extend for the patterns between errors of shortwave radiation and humidity (Fig. 4, SQ) because of the strong correspondence between air temperature and humidity.

Significant correlations between errors in precipitation with those of air temperature and humidity in the central Arctic reflect the underlying processes of evaporation and condensation being closely linked to moisture and temperature (Fig. 4, QP and TP). In general, cold and dry air within the central Arctic results in low precipitation. Based on comparisons with radiosonde profiles, Serreze et al. (2012) suggest that most reanalyses display positive cold-season humidity and temperature biases below the 850-hPa level and thus do not capture observed low-level humidity and temperature inversions for the Arctic and sub-Arctic regions. These biases consequently impact moisture and water vapor estimates in the reanalysis and thus total precipitable water.

Large errors in atmospheric forcing fields discussed in this study have several implications for Arctic Ocean state estimates. For example, wind errors in the Arctic and sub-Arctic regions (Fig. 2) can create large uncertainties in the ocean and ice circulation patterns of these regions (Spreen et al. 2011). Considerable errors in shortwave and longwave fields (Fig. 3) can likely affect solution accuracies in the ocean-ice-atmosphere feedback mechanisms. For instance, a $1 \mathrm{~W} \mathrm{~m}^{-2}$ flux imbalance equates to $10 \mathrm{~cm}$ of ice melt in a year, which represents a significant fraction of the ice budget (Bourassa et al. 2013). Substantial errors in air temperature and humidity within the Arctic will create biases in ice melting and formation processes as well as in the heat and salinity budgets of these regions. Significant uncertainties in precipitation create salinity imbalances and particularly affect halocline-driven Arctic circulations. The effect of large uncertainties in surface atmospheric forcing on ocean state estimates is currently being studied and will be reported elsewhere. 


\section{Summary}

In summary, we present estimates of uncertainty in surface atmospheric state fields commonly used to compute air-sea and air-ice fluxes for the Arctic. Uncertainties are derived from comparisons between six reanalysis or reanalysis-based products and satellitebased and in situ estimates of forcing fields. Assessment of individual atmospheric fields suggests that no single product seems to agree better in all fields with reference datasets. Large differences between time-mean and timevariable errors in most atmospheric fields confirm the need to separate them for studying uncertainties as noted by Chaudhuri et al. (2013). The magnitude of uncertainty in all fields is large when compared to the signal. Spatial patterns of these uncertainties for many fields can be broadly classified into ice-free marginal seas and icecovered central Arctic regions. Comparing an estimate of errors among different forcing variables derived from differences between ERA-Interim and NCEP-NCAR shows significant correlations in variables that are most affected by clouds and biases in reanalysis temperature and humidity profiles. Thus, ongoing improvements in cloud parameterizations are expected to markedly decrease uncertainties in reanalysis-derived fields such as downwelling radiation, air temperature, humidity, and precipitation. Further investigation is also needed to determine whether optimization procedures in ocean models should adjust for common sources of error prevalent in the atmospheric forcing fields instead of adjusting each individual forcing field independently as is present practice.

Acknowledgments. This study was supported by NSF Grant ARC-1022733. The authors thank Patrick Heimbach and Gael Forget (MIT) for their comments and Charmaine King (MIT) for data support.

\section{REFERENCES}

Adler, R. F., and Coauthors, 2003: The version 2 Global Precipitation Climatology Project (GPCP) Monthly Precipitation Analysis (1979-present). J. Hydrometeor., 4, 1147-1167, doi:10.1175/1525-7541(2003)004<1147:TVGPCP>2.0.CO;2.

Andersson, A., K. Fennig, C. Klepp, S. Bakan, H. Graß1, and J. Schulz, 2010: The Hamburg Ocean Atmosphere Parameters and Fluxes from Satellite Data-HOAPS-3. Earth Syst. Sci. Data, 2, 215-234, doi:10.5194/essd-2-215-2010.

Bentamy, A., L.-H. Ayina, W. Drennan, K. Katsaros, A. M. Mestas-Nuñez, and R. T. Pinker, 2008: 15 years of ocean surface momentum and heat fluxes from remotely sensed observations. FLUXNEWS, Vol. 5, WCRP Working Group on Surface Fluxes, 14-16. [Available online at http://sail.msk.ru/ newsletter/fluxnews_5_final.pdf.]

Bosilovich, M. G., J. Chen, F. R. Robertson, and R. F. Adler, 2008: Evaluation of global precipitation in reanalyses. J. Appl. Meteor. Climatol., 47, 2279-2299, doi:10.1175/2008JAMC1921.1.
Bourassa, M. A., and Coauthors, 2013: High-latitude ocean and sea ice surface fluxes: Challenges for climate research. Bull. Amer. Meteor. Soc., 94, 403-423, doi:10.1175/BAMS-D-11-00244.1.

Chaudhuri, A. H., R. M. Ponte, G. Forget, and P. Heimbach, 2013 : A comparison of atmospheric reanalysis surface products over the ocean and implications for uncertainties in airsea boundary forcing. J. Climate, 26, 153-170, doi:10.1175/ JCLI-D-12-00090.1.

Comiso, J. C., C. L. Parkinson, R. Gersten, and L. Stock, 2008: Accelerated decline in the Arctic sea ice cover. Geophys. Res. Lett., 35, L01703, doi:10.1029/2007GL031972.

Curry, J., W. B. Rossow, D. Randall, and J. L. Schramm, 1996: Overview of Arctic cloud and radiation characteristics. J. Climate, 9, 1731-1764, doi:10.1175/1520-0442(1996)009<1731: OOACAR $>2.0 . \mathrm{CO} ; 2$.

Dee, D. P., and Coauthors, 2011: The ERA-Interim reanalysis: Configuration and performance of the data assimilation system. Quart. J. Roy. Meteor. Soc., 137, 553-597, doi:10.1002/qj.828.

Dell'Aquila, A., P. M. Ruti, S. Calmanti, and V. Lucarini, 2007: Southern Hemisphere midlatitude atmospheric variability of the NCEP-NCAR and ECMWF reanalyses. J. Geophys. Res., 112, D08106, doi:10.1029/2006JD007376.

Drobot, S. D., J. A. Maslanik, and C. Fowler, 2006: A long-range forecast of Arctic summer sea-ice minimum extent. Geophys. Res. Lett., 33, L10501, doi:10.1029/2006GL026216.

Francis, J. A., 2002: Validation of reanalysis upper-level winds in the Arctic with independent rawinsonde data. Geophys. Res. Lett., 29, 1315, doi:10.1029/2001GL014578.

— E. Eunter, and C.-Z. Zou, 2005: Arctic tropospheric winds derived from TOVS satellite retrievals. J. Climate, 18, 22702285, doi:10.1175/JCLI3407.1.

Griffies, S. M., M. Winton, B. Samuels, G. Danabasoglu, S. Yeager, S. Marsland, and H. Drange, 2012: Datasets and protocol for the CLIVAR WGOMD Coordinated Ocean-Sea Ice Reference Experiments (COREs). 20 pp. [Available online at http://data1.gfdl.noaa.gov/ nnz/mom4/COREv2/doc/CORE_ notes_15feb2012.pdf.]

Holloway, G., and T. Sou, 2002: Has Arctic sea ice rapidly thinned? J. Climate, 15,1691-1701, doi:10.1175/1520-0442(2002)015<1691: HASIRT $>2.0 . \mathrm{CO} ; 2$.

Houghton, J. T., G. J. Jenkins, and J. J. Ephraums, 1990: Climate Change: The IPCC Scientific Assessment. Cambridge University Press, 365 pp.

_, Y. Ding, D. J. Griggs, M. Noguer, P. J. van der Linden, and D. Xiaosu, Eds., 2001: Climate Change 2001: The Scientific Basis. Cambridge University Press, 944 pp.

Huffman, G. J., R. F. Adler, D. T. Bolvin, and G. Gu, 2009: Improving the global precipitation record: GPCP version 2.1. Geophys. Res. Lett., 36, L17808, doi:10.1029/2009GL040000.

Hunke, E. C., and M. M. Holland, 2007: Global atmospheric forcing data for Arctic ice-ocean modeling. J. Geophys. Res., 112, C04S14, doi:10.1029/2006JC003640.

Jakobson, E., T. Vihma, T. Palo, L. Jakobson, H. Keernik, and J. Jaagus, 2012: Validation of atmospheric reanalyses over the central Arctic Ocean. Geophys. Res. Lett., 39, L10802, doi:10.1029/2012GL051591.

Kalnay, E., and Coauthors, 1996: The NCEP/NCAR 40-Year Reanalysis Project. Bull. Amer. Meteor. Soc., 77, 437-471, doi:10.1175/1520-0477(1996)077<0437:TNYRP>2.0.CO;2.

Kistler, R., and Coauthors, 2001: The NCEP-NCAR 50-Year Reanalysis: Monthly means CD-ROM and documentation. Bull. Amer. Meteor. Soc., 82, 247-267, doi:10.1175/ 1520-0477(2001)082<0247:TNNYRM >2.3.CO;2. 
Large, W., and S. G. Yeager, 2004: Diurnal to decadal global forcing for ocean and sea-ice models: The data sets and flux climatologies. NCAR Tech. Rep. TN-460+STR, 105 pp, doi:10.5065/D6KK98Q6.

Onogi, K., and Coauthors, 2005: Japanese 25-Year Re-Analysis Project-Progress and status. Quart. J. Roy. Meteor. Soc., 131, 3259-3268, doi:10.1256/qj.05.88.

Proshutinsky, A., and Coauthors, 2005: Arctic Ocean study: Synthesis of model results and observations. Eos, Trans. Amer. Geophys. Union, 86, 368-371, doi:10.1029/2005EO400003.

Rienecker, M. M., and Coauthors, 2011: MERRA: NASA's Modern-Era Retrospective Analysis for Research and Applications. J. Climate, 24, 3624-3648, doi:10.1175/JCLI-D-11-00015.1.

Rigor, I. G., R. L. Colony, and S. Martin, 2000: Variations in surface air temperature observations in the Arctic, 1979-97. J. Climate, 13, 896-914, doi:10.1175/1520-0442(2000)013<0896: VISATO $>2.0 . \mathrm{CO} ; 2$.

Saha, S., and Coauthors, 2010: The NCEP Climate Forecast System Reanalysis. Bull. Amer. Meteor. Soc., 91, 1015-1057, doi:10.1175/ 2010BAMS3001.1.

Serreze, M. C., and J. A. Francis, 2006: The Arctic amplification debate. Climatic Change, 76, 241-264, doi:10.1007/ s10584-005-9017-y.

_ A. P. Barrett, and J. Stroeve, 2012: Recent changes in tropospheric water vapor over the Arctic as assessed from radiosondes and atmospheric reanalyses. J. Geophys. Res., 117, D10104, doi:10.1029/2011JD017421.

Smith, S. R., P. J. Hughes, and M. A. Bourassa, 2011: A comparison of nine monthly air-sea flux products. Int. J. Climatol., 31, 1002-1027, doi:10.1002/joc.2225.

Sorteberg, A., V. Kattsov, J. Walsh, and T. Pavlova, 2007: The Arctic surface energy budget as simulated with the IPCC AR4 AOGCMs. Climate Dyn., 29, 131-156, doi:10.1007/ s00382-006-0222-9.

Spreen, G., R. Kwok, and D. Menemenlis, 2011: Trends in Arctic sea ice drift and role of wind forcing: 1992-2009. Geophys. Res. Lett., 38, L19501, doi:10.1029/2011GL048970.

Taylor, K. E., 2001: Summarizing multiple aspects of model performance in single diagram. J. Geophys. Res., 106, 7183-7192, doi:10.1029/2000JD900719.

Tjernström, M., J. Sedlar, and M. D. Shupe, 2008: How well do regional climate models reproduce radiation and clouds in the
Arctic? An evaluation of ARCMIP simulations. J. Appl. Meteor. Climatol., 47, 2405-2422, doi:10.1175/2008JAMC1845.1.

Trenberth, K. E., D. P. Stepaniak, and J. M. Caron, 2000: The global monsoon as seen through the divergent atmospheric circulation. J. Climate, 13, 3969-3993, doi:10.1175/1520-0442(2000)013<3969: TGMAST $>2.0 . \mathrm{CO} ; 2$.

Uppala, S. M., and Coauthors, 2005: The ERA-40 Re-Analysis. Quart. J. Roy. Meteor. Soc., 131, 2961-3012, doi:10.1256/ qj.04.176.

Walsh, J. E., W. L. Chapman, and D. H. Portis, 2009: Arctic cloud fraction and radiative fluxes in atmospheric reanalyses. J. Climate, 22, 2316-2334, doi:10.1175/2008JCLI2213.1.

Wild, M., A. Ohmura, H. Gilgen, J. Morcrette, and A. Slingo, 2001: Evaluation of downward longwave radiation in general circulation models. J. Climate, 14, 3227-3239, doi:10.1175/ 1520-0442(2001)014<3227:EODLRI >2.0.CO;2.

Wilson, A. B., D. H. Bromwich, and K. M. Hines, 2012: Evaluation of Polar WRF forecasts on the Arctic System Reanalysis Domain: 2. Atmospheric hydrologic cycle. J. Geophys. Res., 117, D04107, doi:10.1029/2011JD016765.

Wu, B., J. Wang, and J. E. Walsh, 2006: Dipole anomaly in the winter Arctic atmosphere and its association with Arctic sea ice motion. J. Climate, 19, 210-225, doi:10.1175/ JCLI3619.1.

_ J. E. Overland, and R. D'Arrigo, 2012: Anomalous Arctic surface wind patterns and their impacts on September sea ice minima and trend. Tellus, 64A, 18590, doi:10.3402/ tellusa.v64i0.18590.

Zhang, Y., W. B. Rossow, and A. A. Lacis, 1995: Calculation of surface and top-of-atmosphere radiative fluxes from physical quantities based on ISCCP datasets: 1 . Method and sensitivity to input data uncertainties. J. Geophys. Res., 100, 1149-1165, doi:10.1029/94JD02747.

,,,--- V. Oinas, and M. I. Mishchenko, 2004: Calculation of radiative fluxes from the surface to top of atmosphere based on ISCCP and other global data sets: Refinements of the radiative transfer model and the input data. J. Geophys. Res., 109, D19105, doi:10.1029/2003JD004457.

Zhu, J., B. Huang, and M. A. Balmaseda, 2012: An ensemble estimation of the variability of upper-ocean heat content over the tropical Atlantic Ocean with multi-ocean reanalysis products. Climate Dyn., 39, 1001-1020, doi:10.1007/s00382-011-1189-8. 